\title{
Up-Regulated Expression of Matrix Metalloproteinases in Endothelial Cells Mediates Platelet Microvesicle-Induced Angiogenesis
}

\author{
Cheng Sun ${ }^{\mathrm{a}}$ Shi-Bin Feng ${ }^{\mathrm{a}}$ Zheng-Wang Cao ${ }^{\mathrm{b}}$ Jun-Jie Bei ${ }^{\mathrm{a}}$ Qiang Chen ${ }^{\mathrm{a}}$ \\ Wei-Bo Zhao ${ }^{a}$ Xian-Jie Xu ${ }^{a}$ Zhou Zhou ${ }^{b}$ Zheng-Ping Yu ${ }^{b}$ Hou-Yuan Hua
}

aDepartment of Cardiology, Southwest Hospital, Third Military Medical University, Chongqing,

bDepartment of Occupational Health, Third Military Medical University, Chongqing, China

\section{Key Words}

Matrix metalloproteinase - Platelet microvesicle - Angiogenesis - Human umbilical vein endothelial cell

\begin{abstract}
Background/Aims: Platelet microvesicles (PMVs) contribute to angiogenesis and vasculogenesis, but the mechanisms underlying these contributions have not been fully elucidated. In the present study, we investigated whether PMVs regulate the angiogenic properties of endothelial cells (ECs) via mechanisms extending beyond the transport of angiogenic regulators from platelets. Methods: In vitro Matrigel tube formation assay and in vivo Matrigel plug assay were used to evaluate the pro-angiogenic activity of PMVs. The effects of PMVs on the migration of human umbilical vein endothelial cells (HUVECs) were detected by transwell assay and wound-healing assay. Real-time PCR and western blot were conducted to examine mRNA and protein expression of pro-angiogenic factors in HUVECs. Matrix metalloproteinase (MMP) activity was assayed by gelatin zymography. Moreover, the effects of specific MMP inhibitors were tested. Results: PMVs promoted HUVEC capillarylike network formation in a dose-dependent manner. Meanwhile, PMVs dose-dependently facilitated HUVEC migration. Levels of MMP-2 and MMP-9 expression and activity were upregulated in HUVECs stimulated with PMVs. Inhibition of MMPs decreased their pro-angiogenic and pro-migratory effects on HUVECs. Moreover, we confirmed the pro-angiogenic activity of PMVs in vivo in mice with subcutaneous implantation of Matrigel, and demonstrated that blockade of MMPs attenuated PMV-induced angiogenesis. Conclusion: The findings of our study indicate that PMVs promote angiogenesis by up-regulating MMP expression in ECs via mechanism extending beyond the direct delivery of angiogenic factors.
\end{abstract}




\section{Cellular Physiology Cell Physiol Biochem 2017;41:2319-2332 \\ \begin{tabular}{l|l} 
and Biochemistry Published 10.1159/000475651 & $\begin{array}{l}\text { (c) 2017 The Author(s). Published by S. Karger AG, Basel } \\
\text { www.karger.com/cpb }\end{array}$
\end{tabular}}

Sun et al.: PMVs Promote Angiogenesis via Up-Regulation of MMPs

\section{Introduction}

Blood vessels play great roles in the processes of supplying tissues with oxygen and nutrients and disposing of waste [1]. An imbalance in blood vessel growth contributes to the development of numerous malignant, inflammatory, and ischaemic disorders [2]. Angiogenesis is one mode of vessel formation and entails the sprouting of pre-existing vasculature to form new vessels. Angiogenesis requires many coordinated activities, such as endothelial cell (EC) proliferation, migration, and alignment to form vessel-like tube [3]. Many regulators of angiogenesis both endogenous and pharmacological have been described and continue to be identified $[4,5]$.

Platelet microvesicles (PMVs), also known as platelet microparticles (PMPs), are shed from platelets upon activation or apoptosis and commonly defined as lipid membrane vesicles of 0.1-1 $\mu \mathrm{m}$ in size [6]. In recent years, it has become clear that PMVs, similar to platelets, possess important biological functions [7] and are thus involved in various physiological and pathophysiological responses. PMVs also play a great role in neovascularization [8-10] by serving as a tool or mediator through which platelets exert their pro-angiogenic effects, as various molecules that have traditionally been considered soluble and are released by platelets, such as vascular endothelial growth factor (VEGF), platelet-derived growth factor (PDGF) and fibroblast growth factor (FGF), are in fact bound to PMVs [11].

ECs are thought to release a cocktail of angiogeneic factors [3, 12-14], which account for their beneficial effects on vascular homeostasis. Mounting evidences indicate that PMVs not only passively transport various proteins and receptors from platelets or megakaryocytes to recipient cells, but also act as circulating signaling modules by inducing specific responses in target cells. We previously demonstrated that SSL5-PMPs, staphylococcal superantigen-like protein 5 (SSL5)-induced PMPs, provoke inflammatory mediator release in monocytes [15]. Besides, PMVs induce changes in early outgrowth cells (EOCs) secretome towards a more pro-angiogenic profile [10], which plays a pivotal role in vasculogenesis. However, the effects of PMVs on EC secretion of pro-angiogenic factors and whether these effects are involved in angiogenesis are unclear. Thus, we studied the role of PMVs in angiogenesis and explored potential molecules released by ECs that are critical in mediating such action.

\section{Materials and Methods}

\section{Cell culture}

Human umbilical vein endothelial cells (HUVECs) were purchased from Clonetics (mycoplasma negative, C2519AS). The cells were cultured in DMEM medium (Gibco, USA) supplemented with 10\% fetal bovine serum (FBS), 200mM L-glutamine (Gibco) and 1\% (v/v) penicillin/streptomycin (Beyotime Biotechnology, Beijing, China) in a $5 \% \mathrm{CO}_{2}$ humidified atmosphere at $37^{\circ} \mathrm{C}$.

\section{Preparation of Platelet Microvesicles}

Human blood was collected by venipuncture with a 19-gauge needle into acid-citrate-dextrose $(85 \mathrm{mM}$ trisodium citrate, $83 \mathrm{mM}$ dextrose, and $21 \mathrm{mM}$ citric acid) anticoagulant solution. Washed platelets were prepared as previously described [15]. Briefly, Platelet rich plasma (PRP) was obtained by centrifugation of the above sample at $110 \times \mathrm{g}$ for $15 \mathrm{~min}$ to remove RBCs and leukocytes. Platelets were pelleted by centrifugation at $710 \times \mathrm{g}$ for $15 \mathrm{~min}$ and washed three times with CGS buffer $(120 \mathrm{mM}$ sodium chloride, $13 \mathrm{mM}$ sodium citrate, and $30 \mathrm{mM}$ dextrose, $\mathrm{pH}$ 7.0). The final pellet was resuspended in $0.22-\mu \mathrm{m}$ filtered Tyrode's buffer (137mM NaCl, 2.8mM KCl, $12 \mathrm{mM}$ NaHCO3, $1 \mathrm{mM} \mathrm{MgCl} 2,0.4 \mathrm{mM}$ Na2HPO4, 0.1\% BSA, 10mM HEPES, $5.5 \mathrm{mM}$ glucose, pH 7.4) at $3 \times 10^{8} / \mathrm{ml}$. For generation of microvesicles, washed platelets in Tyrode's buffer containing $1 \mathrm{mM} \mathrm{CaCl}_{2}$ were incubated with $30 \mu \mathrm{M}$ thrombin receptor activator peptide 6 (TRAP6, Sigma-Aldrich, St. Louis, MO, USA) for $10 \mathrm{~min}$ at $37^{\circ} \mathrm{C}$. Following the indicated incubation period, the sample was centrifuged at $710 \times \mathrm{g}$ for $15 \mathrm{~min}$ to separate the platelets from microvesicles. The supernatants containing microvesicles were filtered through a $0.8-\mu \mathrm{m}$ filter to remove residual platelets, and pelleted again at $25000 \times$ g for $60 \mathrm{~min}$. Finally, the pellets containing microvesicles were resuspended in Tyrode's 


\section{Cellular Physiology Cell Physiol Biochem 2017;41:2319-2332 \begin{tabular}{l|l} 
and Biochemistry Published online: April 27, 2017 & $\begin{array}{l}\text { C } 2017 \text { The Author(s). Published by S. Karger AG, Basel } \\
\text { www.karger.com/cpb }\end{array}$ \\
\hline
\end{tabular}}

buffer, which were directly used, or snap-frozen at $-80^{\circ} \mathrm{C}$ to avoid repeated freezing and thawing. The amount of PMVs was quantified by both bicinchoninic acid (BCA) protein assay (Beyotime Biotechnology) and flow cytometry as we described previously [15]. We found that $50 \mu \mathrm{g} / \mathrm{ml}$ of protein concentration was equivalent to $6 \times 10^{6} / \mathrm{ml}$ PMVs. Tyrode's buffer was used as a blank control ("Con" in the figures), while the supernatants ("Sup" in the figures) of centrifuged PMVs were used as a vehicle control in the experiments.

\section{Antibody blocking}

Neutralizing monoclonal antibodies (R\&D Systems, Minneapolis, MN, USA) were used to block PMVs and HUVECs interactions. CD40 ligand (CD40L)-mAb (10 $\mu \mathrm{g} / \mathrm{ml}), \mathrm{CD} 40-\mathrm{mAb}(10 \mu \mathrm{g} / \mathrm{ml})$, or/and P-selectin glycoprotein ligand 1 (PSGL-1)-mAb $(50 \mu \mathrm{g} / \mathrm{ml})$ were preincubated with PMVs or HUVECs for 1 hour. Isotype monoclonal antibody of the same concentration was used for a control. Pan-MMP inhibitor GM6001 (25 $\mu \mathrm{M}$, Tocris Bioscience, Bristol, UK), MMP2 inhibitor ARP101 (25 $\mu \mathrm{M}$, Tocris Bioscience, Bristol, UK), and MMP9 inhibitor ab142180 (25 $\mu \mathrm{M}$, Abcam, Cambridge, UK) were preincubated with HUVECs for 1 hours. Dimethylsulfoxide (DMSO) was used for a vehicle control.

\section{In vitro Matrigel tube formation assay}

Matrigel (Corning Costa Co., MA, USA) was thawed on ice at $4^{\circ} \mathrm{C}$ overnight. The solution was added into a 96-well plate $\left(60 \mu \mathrm{L}\right.$ per well) and incubated at $37^{\circ} \mathrm{C}$ for $1 \mathrm{~h}$ to allow matrix gel solidification. Afterwards, the HUVECs were trypsinized and seeded $\left(1 \times 10^{4}\right.$ cells per well $)$ with Tyrode's buffer, supernatants, different concentrations $(10,20$, or $50 \mu \mathrm{g} / \mathrm{ml}$ ) of PMVs, or VEGF $(50 \mathrm{ng} / \mathrm{ml}$, PeproTech Inc, Rocky Hill, USA) in serumfree DMEM. The plate was then incubated at $37^{\circ} \mathrm{C}$ for $6 \mathrm{~h}$. Tube formation was observed under an inverted light microscope (10×), and five representative fields from each well were photographed.

\section{HUVEC proliferation assay}

HUVEC proliferation was assessed by using Cell Counting Kit-8 (CCK-8, Dojindo, Kumamoto, Japan), according to the manufacturer's instructions. Briefly, the cells were seeded into a 96-well plate $\left(3 \times 10^{3}\right.$ cells $/$ well) and then treated with Tyrode's buffer, supernatants and different concentrations $(10,20$, or $50 \mu \mathrm{g} / \mathrm{ml})$ of PMVs in serum-free DMEM for a period of $24 \mathrm{~h}$ and $48 \mathrm{~h}$. After incubation, a CCK-8 solution was added to the medium $\left(1: 10\right.$ ratio) and incubated at $37^{\circ} \mathrm{C}$ for $2-4 \mathrm{~h}$. The OD value was measured by the absorbance at $450 \mathrm{~nm}$ with an Infinite M200 Microplate Reader (Tecan, Austria).

\section{Transwell chamber migration assay}

The capacity of HUVECs to migrate was determined using a Boyden transwell chamber (Corning Costar, Cambridge, MA, USA) with 8.0- $\mu \mathrm{m}$ pore-size polycarbonate filter inserts in 24-well plates. The cells $\left(1 \times 10^{5} / \mathrm{ml}, 100 \mu \mathrm{L}\right)$ were seeded in the upper compartment in the presence of Tyrode's buffer, supernatants, and different concentrations $(10,20$, or $50 \mu \mathrm{g} / \mathrm{ml})$ of PMVs in serum-free DMEM. The lower compartment contained $600 \mu \mathrm{L}$ of DMEM supplemented with $10 \%$ FBS to stimulate cell migration. After incubating for $8 \mathrm{~h}$ at $37^{\circ} \mathrm{C}$, the medium in the upper chamber was aspirated, and the cells on the upper surface of the membrane were removed by gentle scraping with a cotton swab. Following fixation with $4 \%$ paraformaldehyde at room temperature for $20 \mathrm{~min}$ and staining with crystal violet stain solution for $1 \mathrm{~h}$, the migratory cells on the lower surface of the membrane of five random non-overlapping fields were counted.

\section{In vitro wound-healing migration assay}

The HUVECs were seeded into 6-well plates at a density of $5 \times 10^{5} /$ well in DMEM containing $10 \%$ FBS, $200 \mathrm{mM}$ L-glutamine (Gibco) and 1\% (v/v) penicillin/streptomycin. After the cells had grown to 80\% confluence, a vertical line was created by scraping the cells with a sterile disposable pipette tip to make a scratch wound. Then, the cells were washed twice with phosphate buffered saline (PBS) and incubated in FBS-free DMEM with Tyrode's buffer, supernatants, or different concentrations $(10,20$, or $50 \mu \mathrm{g} / \mathrm{ml})$ of PMVs. After incubating for $12 \mathrm{~h}$ and $24 \mathrm{~h}$, the cells that had migrated to the wound areas were photographed with an inverted light microscope.

RNA isolation and RT-qPCR

RNA was extracted using RNAiso Plus (Takara Bio Inc., Otsu, Japan) and cDNAs were synthesized by a PrimeScript $^{\mathrm{TM}}$ RT Reagent Kit with gDNA Eraser (Takara). The primers used in the real-time PCR analyses 


\section{Cellular Physiology Cell Physiol Biochem 2017;41:2319-2332 and Biochemistry Published online: April 27, $2017 \quad \begin{aligned} & \text { DOI: 10.1159/000475651 } 2017 \text { The Author(s). Published by S. Karger AG, Basel } \\ & \text { www.karger.com/cpb }\end{aligned}$ \\ Sun et al.: PMVs Promote Angiogenesis via Up-Regulation of MMPs}

Table 1. Primers used in the quantitative real-time PCR analyses

\begin{tabular}{|c|c|c|}
\hline Gene & Forward primer & Reverse primer \\
\hline HIF-1 $\alpha$ & ${\text { 5'-TTTTGGCAGCAACGACACAG- } 3^{\prime}}^{\prime}$ & 5'-GCGGTGGGTAATGGAGACAT-3' \\
\hline VEGF-A & 5'-CGGCCTTCGCTTACTCTCAC-3' & 5'-TCATGGGCTGCTTCTTCCAA-3' \\
\hline PDGF & $5^{\prime}$-CCATTCCCGAGGAGCTTTATG-3' & 5'- CAGCAGGCGTTGGAGATCAT-3' \\
\hline IL-8 & 5'-AGTCCTTGTTCCACTGTGCC-3' & 5'-AGTGCTTCCACATGTCCTCAC-3' \\
\hline MMP-2 & 5'-GATACCCCTTTGACGGTAAGGA-3' & 5'-ССТTCTCCCAAGGTCCATAGC-3' \\
\hline MMP-7 & 5'-GGATGGTAGCAGTCTAGGGATTAACT-3' & 5'-GGAATGTCCCATACCCAAAGAA-3' \\
\hline MMP-9 & $5^{\prime}$-TATGACATCCTGCAGTGCCC-3' & 5'-TTGTATCCGGCAAACTGGCT-3' \\
\hline TIMP-1 & 5'-ACCACCTTATACCAGCGTTATGA-3' & 5'-GGTGTAGACGAACCGGATGTC-3' \\
\hline GAPDH & 5'-TTTGGCTACAGCAACAGGGT-3' & 5'-GGGAGATTCAGTGTGGTGGG-3' \\
\hline
\end{tabular}

are listed in Table 1. The PCR amplification protocol involved 40 cycles of denaturation at $95^{\circ} \mathrm{C}$ for 10 seconds, primer annealing at $59^{\circ} \mathrm{C}$ for 20 seconds and primer extension at $72^{\circ} \mathrm{C}$ for 10 seconds. Each sample was analyzed at least in triplicates.

\section{Western blot analysis}

The cells were harvested and lysed in RIPA buffer (Beyotime Biotechnology) that contained a cocktail of both protease and phosphatase inhibitors (Roche, Basel, Switzerland). Protein concentrations were determined by BCA protein assay (Beyotime Biotechnology). The protein samples were subjected to $10 \%$ SDS-PAGE. After the proteins were transferred to PVDF membranes, the membranes were blocked and incubated with various primary antibodies at $4^{\circ} \mathrm{C}$ overnight. Anti-phospho-Erk1/2 (Thr185/Tyr187), antiErk1/2, anti-phospo-Akt (Ser473), and anti-Akt (Ser473) were purchased from Cell Signaling Technology, and anti-MMP2, anti-MMP7, anti-MMP9, and anti-TIMP-1 were purchased from Abcam. GAPDH (Sigma) was used as a loading control. The protein blots were visualized using an ECL Western Blotting Kit (Millipore, Boston, MA, USA).

\section{Gelatin zymography}

MMP-2/MMP-9 protein abundance and activation in conditioned medium were analyzed by gelatin zymography as described previously $[15,16]$. Briefly, HUVECs were incubated in the presence of Tyrode's buffer, supernatants, or different concentrations $(10,20$, or $50 \mu \mathrm{g} / \mathrm{ml}$ ) of PMVs in serum-free medium for 24 hours. Equivalent amounts (protein concentration) of cell culture supernatants quantified by BCA protein assay method were run on $10 \%$ SDS-polyacrylamide gels copolymerized with $1 \mathrm{mg} / \mathrm{ml}$ of gelatin (Sigma) in Laemmli's sample buffer (Bio-Rad Laboratories Inc). After electrophoresis, gels were washed twice for 45 minutes in $2.5 \%$ Triton X-100, agitated in development buffer $(0.05 \mathrm{M}$ Tris- $\mathrm{HCl} \mathrm{pH} \mathrm{8.8,200} \mathrm{mM} \mathrm{NaCl,} 5 \mathrm{mM}$ $\mathrm{CaCl}_{2}, 0.02 \% \mathrm{NaN}_{3}$ ) for 15 minutes at room temperature and then transferred to a $37^{\circ} \mathrm{C}$ incubator for 24 hours. After incubation, gels were immersed in fixing/destaining solution (methanol: acid: water, 4.5:1:4.5, $\mathrm{v}: \mathrm{v}: \mathrm{v}$ ) at room temperature for 15 minutes and stained in Coomassie brilliant blue R250 solution (Beyotime Biotechnology) for 1 hours. Finally, gels were destained properly with fixing/destaining solution and were visualized using Molecular Imager ${ }^{\circledR}$ ChemiDocTM XRS+ (Bio-Rad Laboratories Inc). Densitometric quantification of gelatinolytic activity of the band was measured in terms of pixel intensity by the Image LabTM Software (Bio-Rad Laboratories Inc).

\section{In vivo Matrigel plug assay}

Matrigel plug assay was performed as previously described [17]. The in vivo angiogenesis protocol using a murine model of Matrigel plug subcutaneous implantation was approved by the Animal Ethics Committee of Third Military Medical University. Male C57BL/6 mice (6-8 weeks) were obtained from the Laboratory Animal Center of Third Military Medical University.

Mice were received subcutaneous injection using a 25-gauge needle in the right flanks of Matrigel gel $(400 \mu \mathrm{L})$ containing Tyrode's buffer, supernatants, PMVs $(50 \mu \mathrm{g} / \mathrm{ml})$, PMVs $(50 \mu \mathrm{g} / \mathrm{ml})$ plus different MMP inhibitors, VEGF $(50 \mathrm{ng} / \mathrm{ml})$ or VEGF with GM6001 $(25 \mu \mathrm{M})$, respectively. The Matrigel plugs were removed two weeks after implantation and photographed under a modular stereo microscope (Leica MZ10 F, Wetzlar, Germany), after which one portion of the plugs was fixed in $4 \%$ paraformaldehyde overnight, embedded in paraffin, and sectioned for hematoxylin and eosin (H\&E)-staining. 
Statistical analysis

Data analysis was performed using the GraphPad Prism 5.0 software package (San Diego, CA, USA). All experimental data are expressed as the mean \pm standard error of the mean (SEM), and each experiment was repeated at least three times, unless otherwise stated. Data comparisons were performed using Student's t-test or one-way analysis of variance (ANOVA), and $P<0.05$ was considered statistically significant.

\section{Results}

PMVs promote HUVEC tube formation in vitro

We examined the effect of PMVs on HUVEC tube formation with an in vitro Matrigel model. HUVECs were seeded on a Matrigel substrate supplemented with Tyrode's buffer, supernatants, or different concentrations $(10,20$, or $50 \mu \mathrm{g} / \mathrm{ml})$ of PMVs, and VEGF was set as a positive control. The results showed that PMVs enhanced HUVEC tube formation in a dosedependent manner (Fig. $1 \mathrm{~A}$ and B), while the supernatants also induced a slight increase in capillary-like tube formation compared with the blank controls.

\section{Effects of PMVs on HUVEC proliferation and migration}

Proliferation and migration of ECs are involved in the process of angiogenesis. The CCK8 assay data showed that supernatants and PMVs promoted HUVEC proliferation and that the enhancements of HUVEC proliferation were similar compared with the blank controls (Fig. $2 \mathrm{~A}$ and $\mathrm{B}$ ). In addition, we determined the effects of PMVs on HUVEC motility by performing a Boyden chamber chemotactic migration assay and found that PMVs treatment led to dose-dependent promotion of HUVEC migration (Fig. $2 \mathrm{C}$ and D). Furthermore, our woundhealing assay also showed that HUVEC wound healing was gradually accelerated in a PMV concentration-dependent manner when determined at both $12 \mathrm{~h}$ and $24 \mathrm{~h}$ (Fig. $2 \mathrm{E}$ and F).

Fig. 1. PMVs promote HUVEC tube formation. (A) An in vitro angiogenesis assay of HUVECs was performed on Matrigel cast in a 96-well culture plate. Tube formation of HUVECs $\left(1 \times 10^{4}\right.$ per well $)$ in the presence of Tyrode's buffer (Con), supernatants (Sup), and different concentrations $(10,20$, or $50 \mu \mathrm{g} /$ $\mathrm{ml}$ ) of PMVs were observed after a 6 h-culture using an LEICA DMIRB microscope. VEGF (50 ng/ $\mathrm{ml}$ ) was set as a positive control. Images from five randomly selected fields were acquired $(10 \times)$. Images shown are representatives of five independent experiments. (B) Tube number was counted in each field, and the tube number of each treatment was reported as the mean of the counts from five randomly fields $(n=5)$. Data are presented as the mean \pm SEM. ${ }^{* *} P<$ 0.01 vs. Con. ${ }^{\# \#} P<0.01$ vs. Sup. ${ }^{\$} \mathrm{P}<$ 0.05 vs. PMVs $(50 \mu \mathrm{g} / \mathrm{ml})$. Scale bar represents $100 \mu \mathrm{m}$.

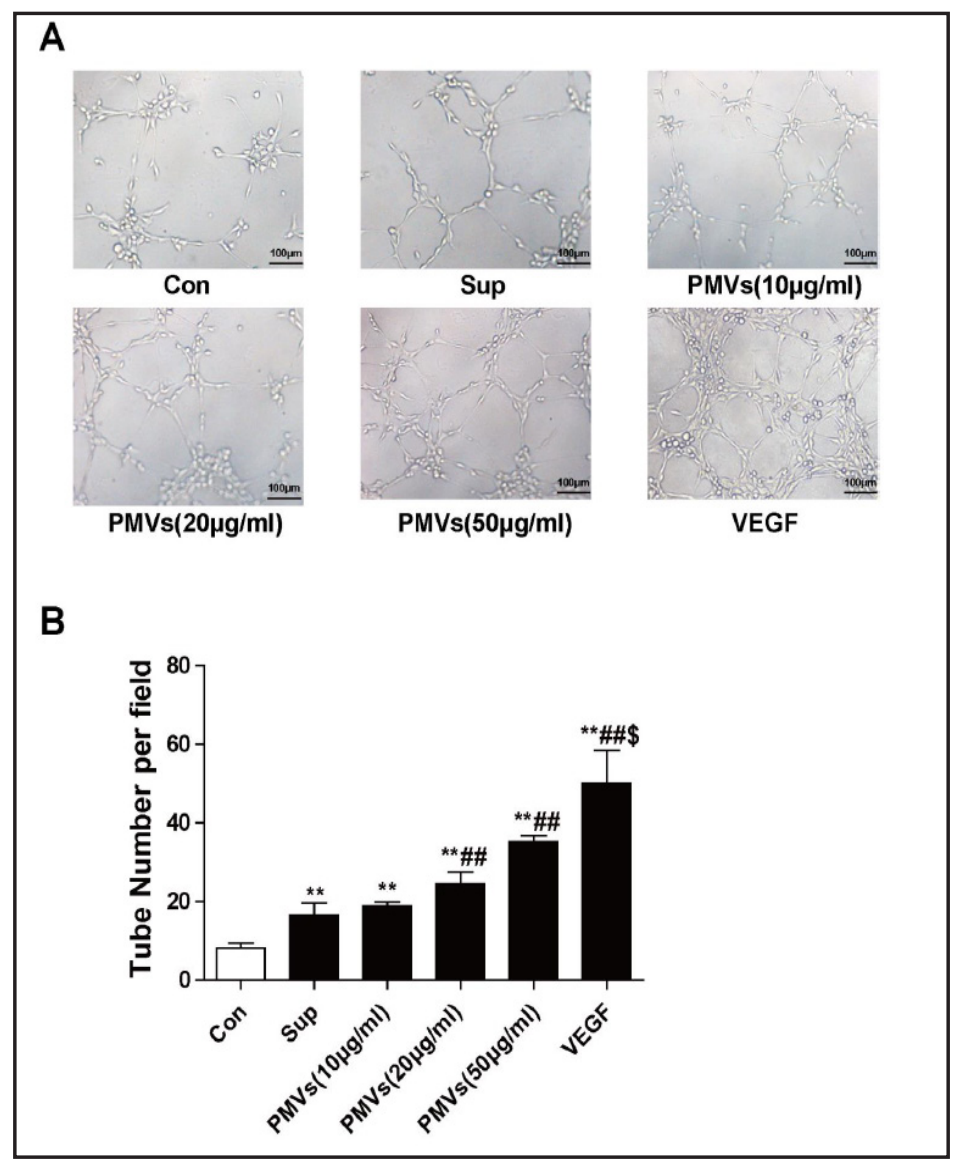


A

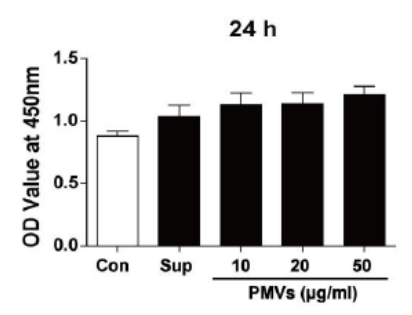

$c$

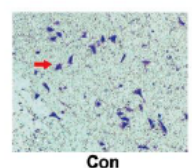
Con

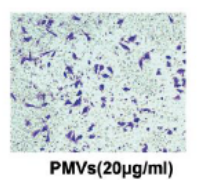

$E$

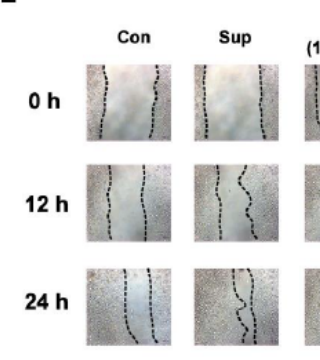

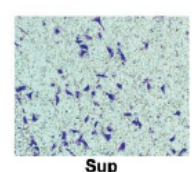

Sup

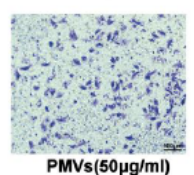

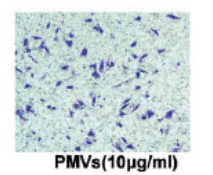

D
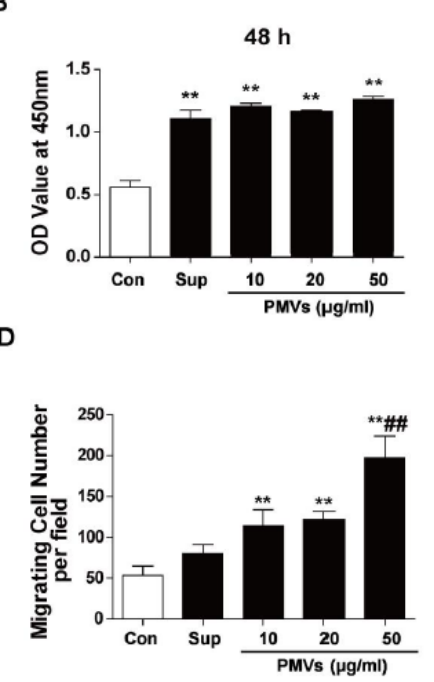

$\mathbf{F}$
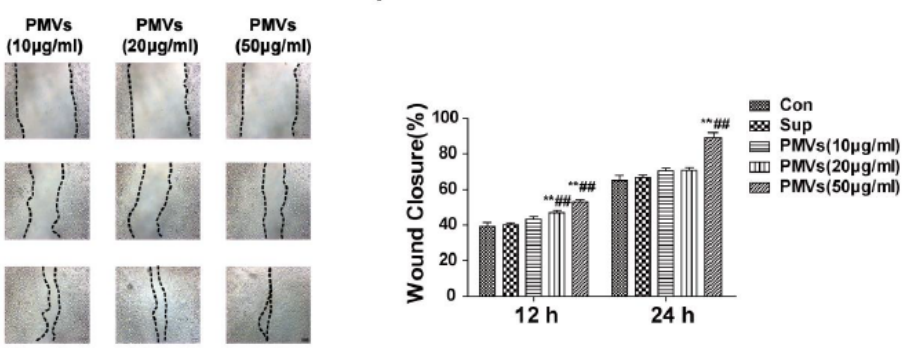

Fig. 2. Influences of PMVs on HUVEC proliferation and migration. After HUVECs were cultured in the presence of Tyrode's buffer (Con), supernatants (Sup), and different concentrations $(10,20$, or $50 \mu \mathrm{g} / \mathrm{ml}$ ) of PMVs for $24 \mathrm{~h}$ (A) or $48 \mathrm{~h}$ (B). CCK-8 assay was used to detect the proliferation of the cells $(\mathrm{n}=3)$. (C) Images of Boyden transwell assay of HUVECs treated with or without PMVs. (D) The number of HUVECs that migrated to the lower side of the membranes after incubation for $8 \mathrm{~h}$ is shown $(\mathrm{n}=3$ ). (E) Images of wound-healing assay of HUVECs at 0,12 and $24 \mathrm{~h}$ after scratch wound placements. (F) The percent wound closure at 12 and $24 \mathrm{~h}$ after scratch wound placements is shown $(\mathrm{n}=3)$. Data are presented as the mean \pm SEM. ${ }^{* *} P<0.01$ vs. Con. ${ }^{\#} P<0.01$ vs. Sup. Scale bar represents $100 \mu \mathrm{m}$.

\section{PMVs up-regulate MMP-2 and MMP-9 expression and activity in HUVECS}

We investigated the mechanism underlying PMV-induced HUVEC tube formation and migration further. We first analyzed the effects of PMVs on the expression of some common pro-angiogenic factors. Interestingly, HIF-1 $\alpha$, VEGF-A, PDGF mRNA levels remained unchanged, while IL-8 levels were significantly reduced (Fig. 3A). Numerous studies have indicated that matrix metalloproteinases (MMPs), such as MMP-2, MMP-7, MMP-9 and TIMP-1, which mediate the process of extracellular matrix (ECM) remodeling, play a critical role in cell migration progress, and are a prerequisite for angiogenesis [18-22]. Thus, we next assessed the production of the four MMPs involved in angiogenesis. The quantitative real-time PCR and western blotting results showed that PMVs dose-dependently stimulated MMP-2 and MMP-9 expression in HUVECs, while there was no change in MMP-7 and TIMP1 production (Fig. $3 \mathrm{~A}, \mathrm{~B}$ and C). Moreover, gelatin-zymography analysis showed that PMVs significantly stimulated synthesis and activation by HUVECs of MMP-2 and MMP-9 in a dose-dependent manner, while MMP-2 and MMP-9 derived from PMVs did not measurably contribute to gelatinolytic activity (Fig. $3 \mathrm{D}$ and E).

\section{KARGER}




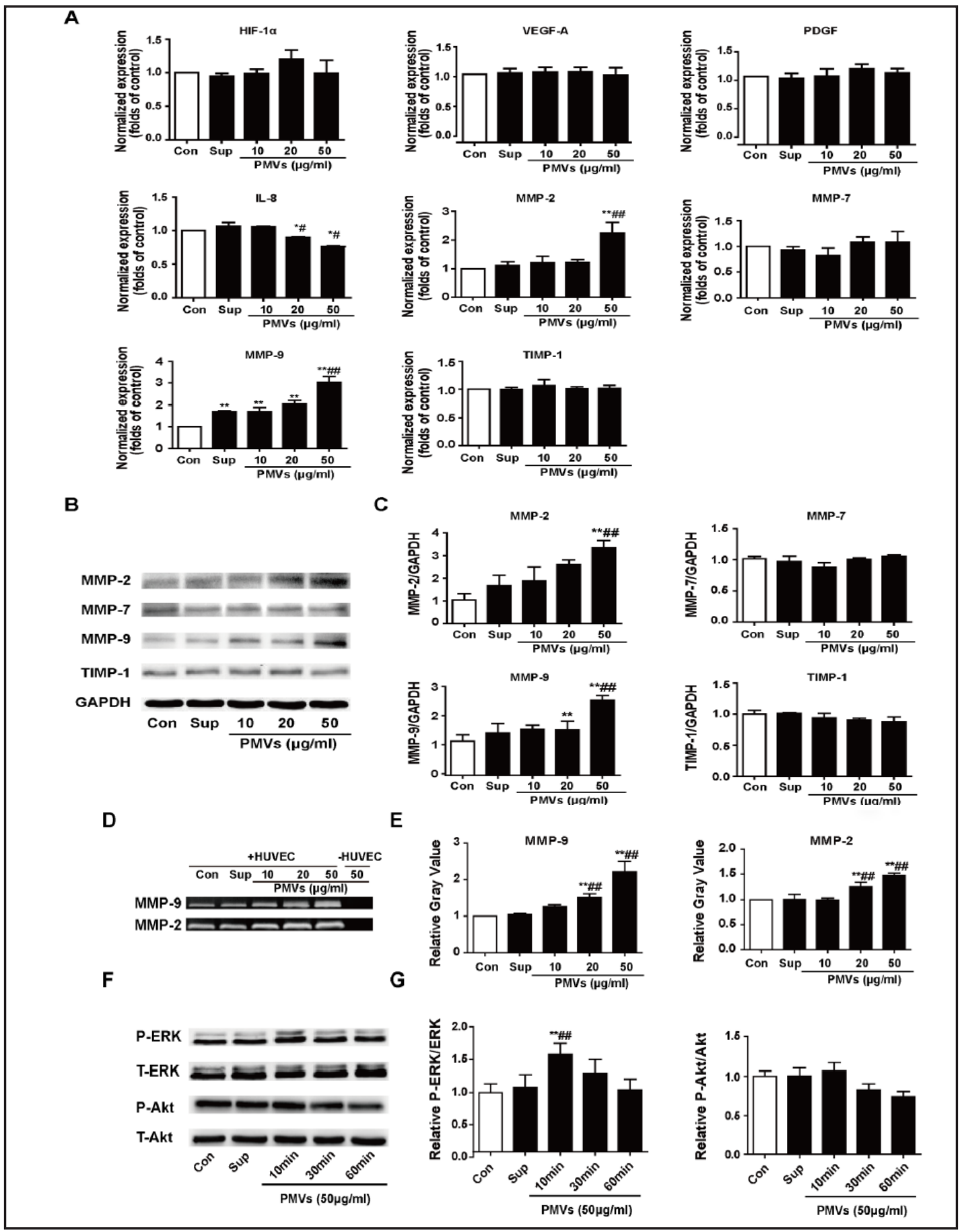

Fig. 3. Effects of PMVs on the expression of angiogenesis-related molecules in HUVECs. (A) qPCR analysis of angiogenesis-related factors mRNA expression after treatment for $24 \mathrm{~h}$ as described in the Materials and Methods ( $\mathrm{n}=3$ ). (B) MMPs and TIMP-1 protein expression were determined by western blot and normalized to the GAPDH levels. (C) The protein bands were quantified by densitometric analysis (n = 3). (D) Representative zymograms of cell supernatants subjected to gel electrophoresis. (E) The gelatinolytic activity of the transparent bands was quantified by densitometric analysis $(n=3)$. (F) HUVECs were treated with Tyrode's buffer (Con), supernatants (Sup), and different concentrations of PMVs (50 $\mathrm{g} / \mathrm{ml}$ ) for 0-60 min. The levels of phosphorylated and total of ERK1/2 and Akt were assessed by western blot analysis. (G) The protein bands were quantitated by densitometric analysis $(\mathrm{n}=3)$. Data are presented as the mean \pm SEM. ${ }^{*} P$ $<0.05,{ }^{* *} P<0.01$ vs. Con. ${ }^{\#} \mathrm{P}<0.05,{ }^{\# \# P} 0.01$ vs. Sup. 


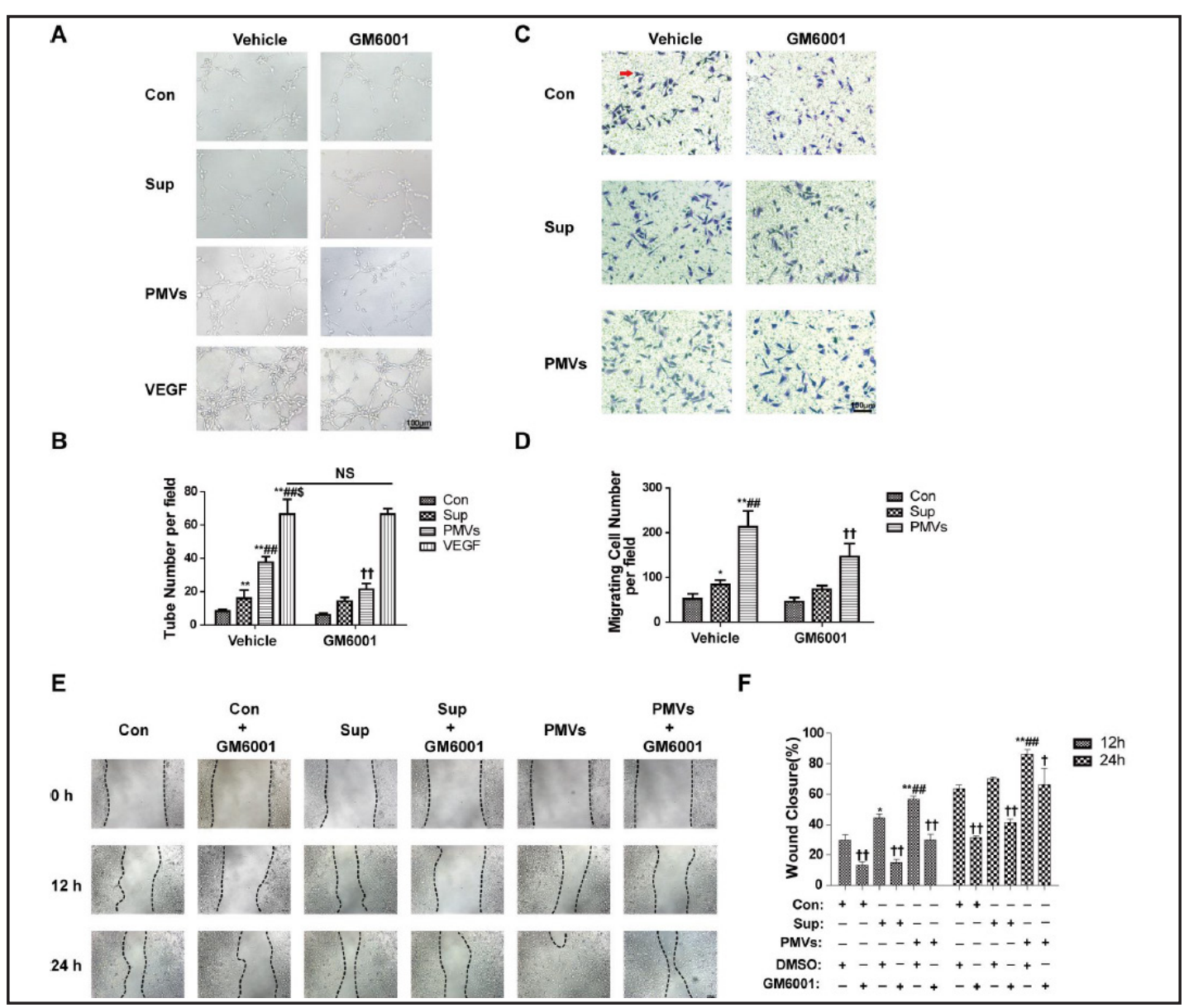

Fig. 4. Pan- MMP inhibitor weakens PMV promotion of HUVEC tube formation and migration. HUVECs were pretreated with the pan-MMP inhibitor GM6001 (25 $\mu \mathrm{M})$ for 1 hour, and co-cultured with Tyrode's buffer (Con), supernatants (Sup), and PMVs (50 $\mathrm{g} / \mathrm{ml}$ ) for $6 \mathrm{~h} \mathrm{(A),} 8 \mathrm{~h}$ (C), and $24 \mathrm{~h}$ (E). Representative images of in vitro angiogenesis assays (VEGF (50 ng/ml) was set as a positive control), transwell assays and wound-healing assays are shown. (B) The tube number of each treatment is shown ( $n=5)$. (D) The number of HUVECs per treatment that migrated to the lower side of the membranes is shown $(n=3)$. (E) The percent wound closure at 12 and $24 \mathrm{~h}$ after scratch wound placements is shown $(\mathrm{n}=3)$. Data are presented as the mean \pm SEM. ${ }^{*} P<0.05,{ }^{* *} P<0.01$ vs. Con, ${ }^{\# \#} P<0.01$ vs. Sup, ${ }^{\$} \mathrm{P}<0.05$ vs. PMVs (50 $\left.\mu \mathrm{g} / \mathrm{ml}\right)$, and ${ }^{\dagger} P<0.05,{ }^{\dagger+} P<$ 0.01 vs. Con, Sup, PMVs treatment without inhibitor. Scale bar represents $100 \mu \mathrm{m}$.

\section{PMVs promote HUVEC tube formation and migration by promoting MMP secretion}

We sought to determine the role of MMPs in PMV pro-angiogenic activity using the MMP inhibitors. Firstly, HUVECs were pretreated with pan-MMP inhibitor GM6001 (25 $\mu \mathrm{M})$ for $1 \mathrm{~h}$. As shown in Fig. 4 A and B, PMV-enhanced tube formation was markedly inhibited by GM6001, while there was no difference between the two groups with VEGF in the absence or presence of GM6001. In addition, the Boyden transwell migration assay and wound-healing assay results both showed that MMP inhibition by GM6001 significantly weakened the HUVEC migration enhancements stimulated by PMVs (Fig. 4 C, D, E and F). Besides, differential role of MMP2 and MMP9 were further defined by using specific inhibitors. As shown in Fig. 5, MMP-2 and MMP-9 inhibitors both weaken the PMV-enhanced tube formation and migration. Interestingly, the effecacy of MMP-2 inhibitor surpassed that of MMP-9 inhibitor. These results suggested that MMPs are pivotal in PMV-induced HUVEC tube formation and migration enhancements, and that MMP-2 plays a more important role than MMP-9.

Furthermore, we also explored the potential molecular basis of PMVs and HUVECs interactions resulting in angiogenesis. Platelet-derived P-selectin and CD40L are two KARGER 


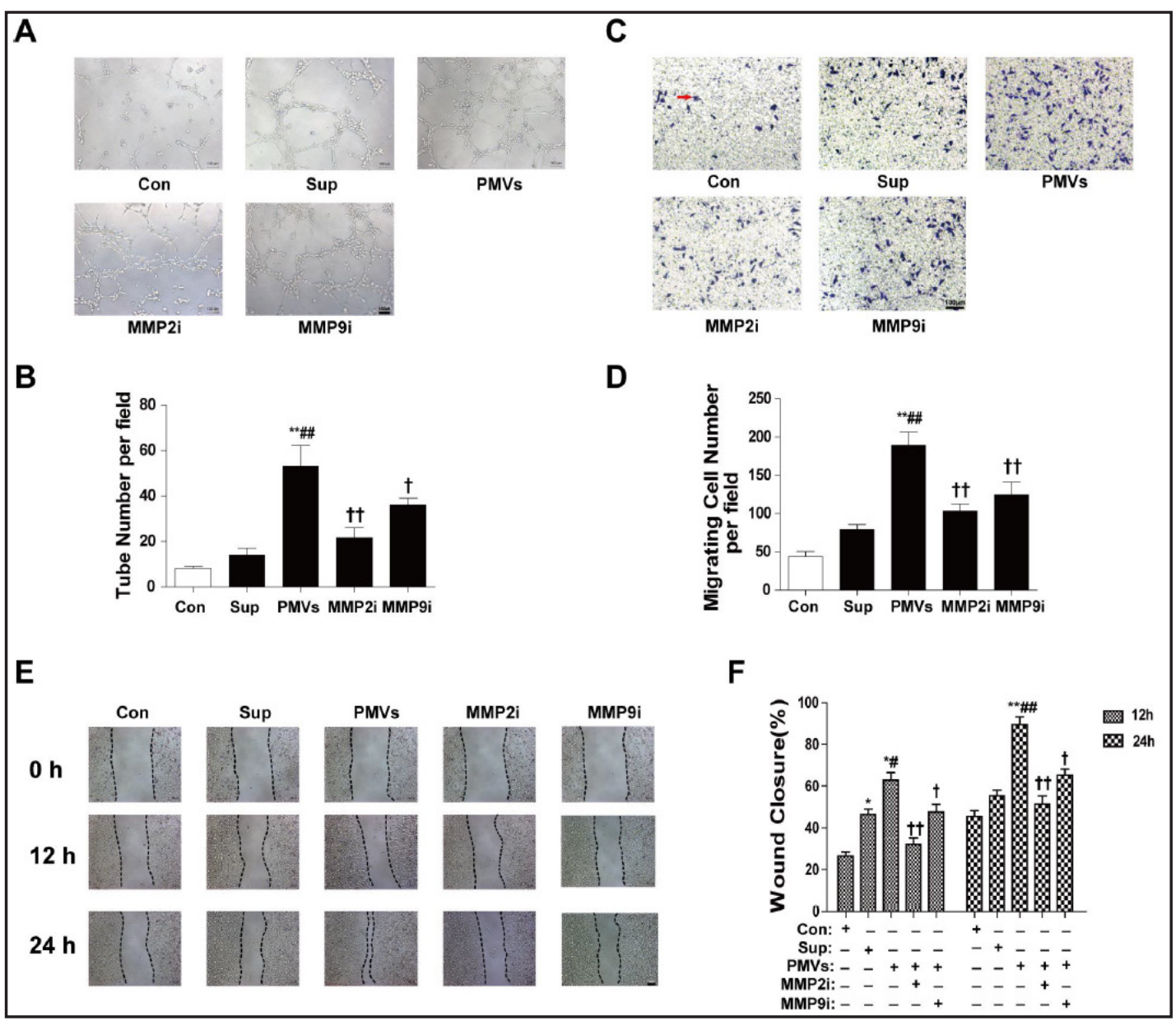

Fig. 5. Effects of specific MMP-2 and MMP-9 inhibitors on PMV-enhanced angiogenesis. HUVECs were treated PMVs $(50 \mu \mathrm{g} / \mathrm{ml})$ in the presence of the MMP-2 inhibitor (MMP2i) ARP101 (25 $\mu \mathrm{M})$ and MMP-9 inhibitor (MMP9i) ab142180 (25 $\mu \mathrm{M})$ for $6 \mathrm{~h} \mathrm{(A),} 8 \mathrm{~h}(\mathrm{C})$, and $24 \mathrm{~h}$ (E). Representative images of in vitro angiogenesis assays, transwell assays and wound-healing assays are shown. (B) The tube number of each treatment is shown ( $n=5)$. (D) The number of HUVECs per treatment that migrated to the lower side of the membranes is shown $(\mathrm{n}=3)$. (E) The percent wound closure at 12 and $24 \mathrm{~h}$ after scratch wound placements is shown $(\mathrm{n}=3)$. Data are presented as the mean \pm SEM. ${ }^{*} \mathrm{P}<0.05$, ${ }^{* *} \mathrm{P}<0.01$ vs. Tyrode's buffer $(\mathrm{Con}),{ }^{*} \mathrm{P}<0.05$, ${ }^{\#} \mathrm{P}<$ 0.01 vs. supernatants (Sup), and ${ }^{\dagger} \mathrm{P}<0.05,{ }^{\dagger} \mathrm{P}<0.01$ vs. Con, Sup, PMVs treatment without inhibitors. Scale bar represents $100 \mu \mathrm{m}$.

important molecules involved in angiogenesis $[23,24]$. P-selectin and CD40L are known to mediate platelet-endothelial cell (EC) interactions by binding to their respective receptors PSGL-1 and CD40 expressed on ECs [25]. We observed that CD40L or CD40 blocking antibodies had no effect on PMV-enhanced tube formation, nor for the use of PSGL-1 mAb to block P-selectin binding to PSGL-1 (Fig. 6).

PMVs enhance angiogenesis mediated by MMPs in vivo

We exploited pro-angiogenic effect of PMVs in vivo in mice with Matrigel plug implants. As shown in Fig. 7A, a 2-week implantation of Matrigel plugs containing Tyrode's buffer and supernatants did not induce marked new vessel formation. However, Matrigel plugs containing PMVs induced significant angiogenesis, and the new vessels were much better developed, as evidenced by a more intense branching of the new vessels. In contrast, Matrigel plugs containing PMVs mixed with MMP inhibitors induced considerably less angiogenesis than their counterparts, and the new vessels were less well developed and 
Fig. 6. Lack of effect of CD40LCD40 and P-selectin-PSGL-1 interactions in PMV-enhanced angiogenesis. HUVECs were treated with PMVs $(50 \mu \mathrm{g} / \mathrm{ml})$ in the presence of anti-CD $40 \mathrm{~L}(10 \mu \mathrm{g} / \mathrm{ml})$, anti-CD40 $(10 \mu \mathrm{g} / \mathrm{ml})$ monoclonal antibody (A) or anti-PSGL-1 $(50 \mu \mathrm{g} / \mathrm{ml})$ monoclonal antibody (B) for 6 hours. Representative images of in vitro angiogenesis assays are shown in the left panel. The tube number of each treatment is shown in the right panel $(n=5)$. Data are presented as Mean \pm SEM. ${ }^{* *} \mathrm{P}<0.01$ vs. Tyrode's buffer (Con), ${ }^{\# \#} \mathrm{P}<0.01$ vs. supernatants (Sup), Scale bar represents $100 \mu \mathrm{m}$.

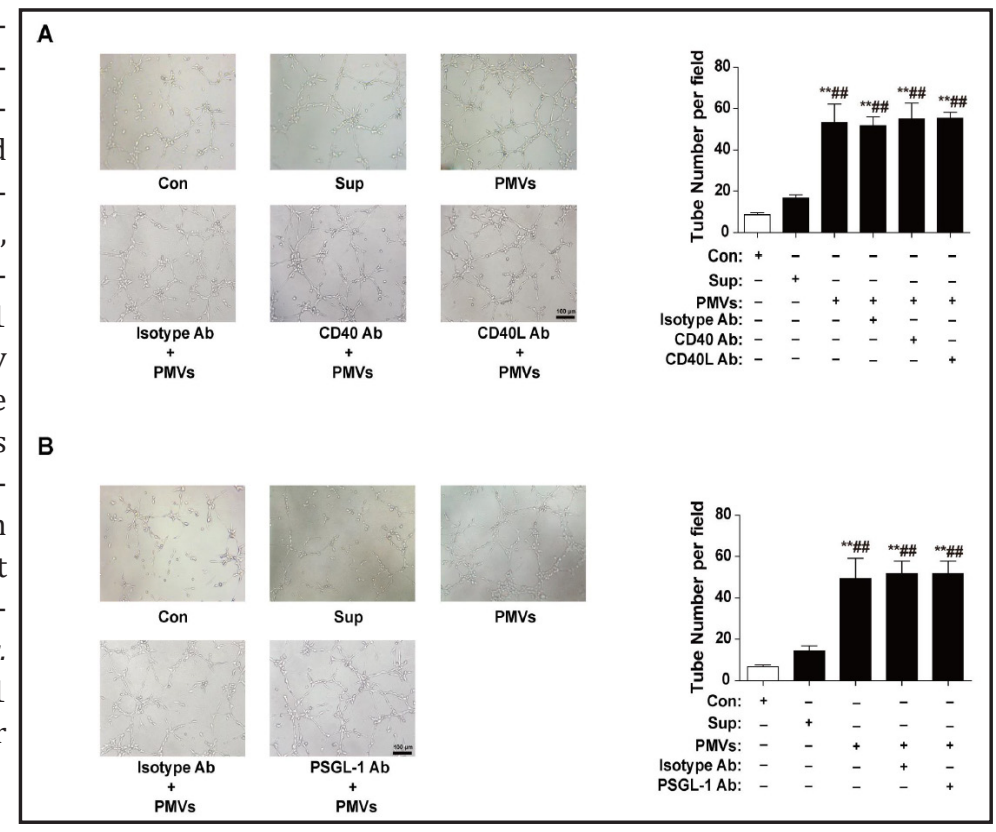

with limited branches than those induced by their counterparts. This is in contrast to the lack of effect of pan-MMP inhibitor GM6001 in VEGF-enhanced angiogenesis. Besides, the inhibitory effect of MMP-2 inhibitor also surpassed that of MMP-9 inhibitor in vivo. When branch numbers of newly formed vessels were counted, PMVs induced significantly more angiogenesis than tyorde's buffer and supernatants, MMP inhibitors could markedly weaken PMV enhancement of vessel formation, while MMP inhibition had no effect on VEGF-induced angiogenesis in vivo (Fig. 7B). The H\&E staining of paraffin-embedded Matrigel plug sections also revealed that new vessel formation was rare in the two control plugs, most intense and well-developed in PMV plugs, and thinly scattered in the plugs supplemented with PMVs and MMP inhibitors (Fig. 7C).

\section{Discussion}

Of the microvesicles circulating in blood, $70 \%$ to $90 \%$ are derived from platelets [15, $26]$ in response to various stimuli, such as ADP, collagen, thrombin, or following complement activation [27]. Since platelet activation, characteristically occurs at the sites of blood flow disturbances or endothelial injury, where angiogenesis takes place (e.g., in tumor vasculature [28], or in proximity to thickened tunica intima [29]), the possible impact of PMVs on blood vessel development is an important issue.

Previous studies have demonstrated that PMVs, which serve as a source of cytokines and growth factors, may be involved in angiogenesis and vasculogenesis [8-10, 30]. Consistent with these findings, our experiments revealed that PMVs enhanced sprouting angiogenesis in vitro and in vivo. It is proposed that platelets exhibit pro-angiogenic activity via both membrane proteins and platelet releasates [11, 31, 32]. Indeed, we found that the supernatants of centrifuged PMVs, which are similar to platelet releasates but lack PMVs, slightly enhanced HUVEC tube formation, compared with Tyrode's buffer, findings in line with those of the above studies. Additionally, we showed that PMVs promoted HUVEC proliferation in a non-dose-dependent manner, similar to the supernatants. Kim et al. reported that PMVs concentration-dependently facilitate EC proliferation [8]. Such discrepancy may be due to the fact that they only used the blank control in their experiments. Our transwell assay and wound-healing assay results further indicated that PMVs increased HUVEC migration, compared with the both negative controls. Thus, the pro-angiogenic activity of

\section{KARGER}




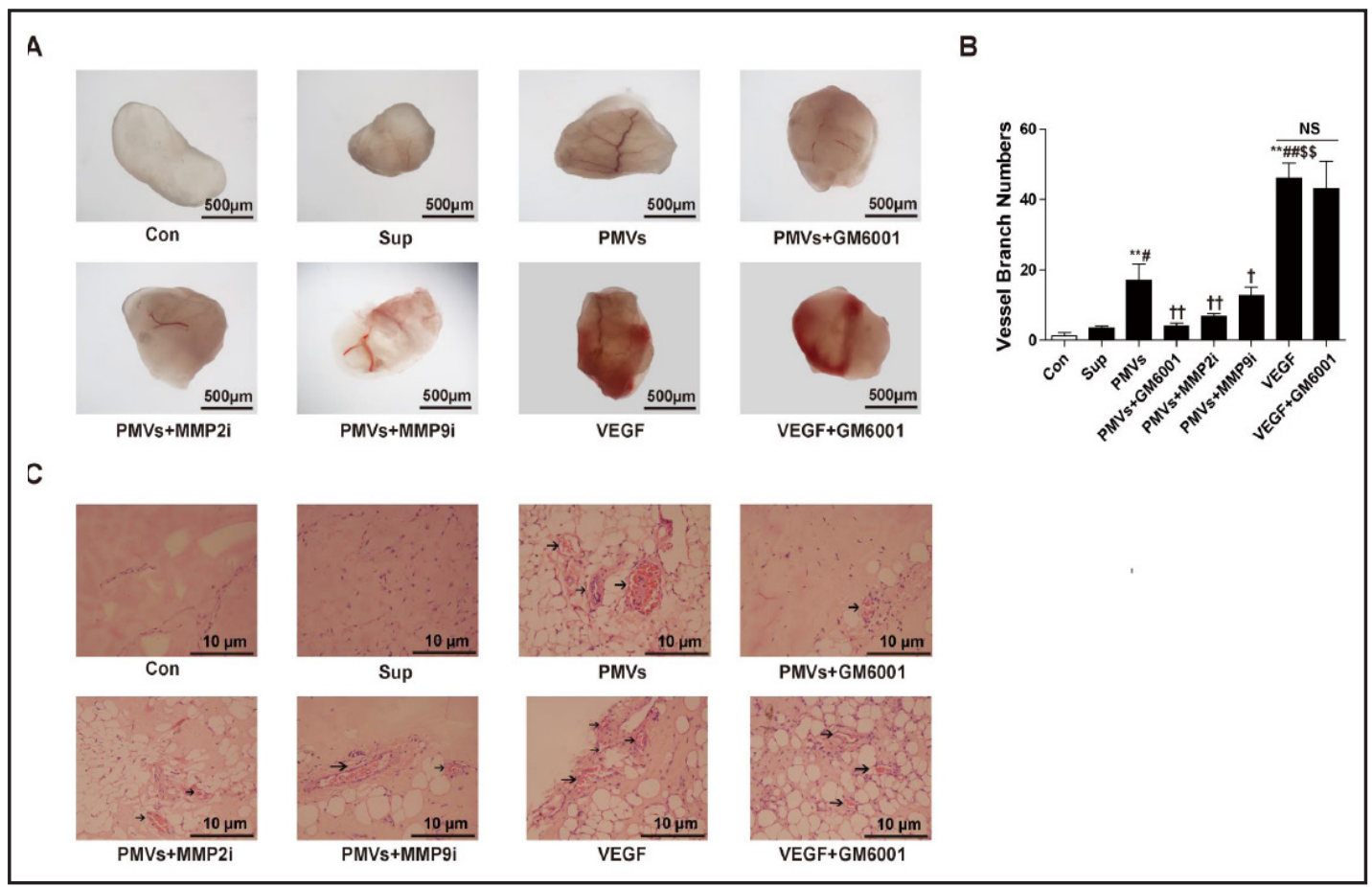

Fig. 7. PMVs promote angiogenesis mediated by MMPs in vivo. (A) Photographs of each Matrigel plug harvested from mice were taken under a modular stereo microscope (Leica MZ10 F, Wetzlar, Germany), 8×. (B) Angiogenesis intensity was assessed according to the numbers of new vessel branches that formed in the Matrigel plugs $(\mathrm{n}=6)$; Data are presented as the mean \pm SEM. ${ }^{* *} P<0.01$, vs. Tyrode's buffer (Con); ${ }^{*} P<$ $0.05,{ }^{\# \#} \mathrm{P}<0.01$ vs. supernatants (Sup), ${ }^{\$ \$} \mathrm{P}<0.01$ vs. PMVs $(50 \mu \mathrm{g} / \mathrm{ml}),{ }^{\dagger} P<0.05,{ }^{\dagger \dagger} \mathrm{P}<0.01$ vs. PMVs without inhibitor. (C) Paraffin-embedded implantation plug sections were stained with hematoxylin and eosin. New vessel formation (black arrowheads) was observed at 200x.

PMVs surpasses that of supernatants because of the superior ability of PMVs in promoting endothelial cell migration.

It's well known that PMVs, like cargo carriers, passively carry and transport an array of platelet-derived products, including adhesive molecules such as glycoprotein (GP)-Ib $\alpha$, GPIIb/IIIa, P-selectin and CD40L; chemokines; bioactive lipids; inflammatory proteins and microRNAs to recipient cells, regulating intracellular signaling or gene transcription of target cells [33-35]. We and others have demonstrated that PMVs interact with monocytes and modulate their pro-inflammatory functionality [15, 36, 37]. Mause et al. showed that PMVs shift the multifaceted secretome of EOCs toward a more pro-angiogenic composition featuring elevated levels of angiogenic growth factors, such as VEGF and epidermal growth factor (EGF), but not MMPs [10]. In the current study, we showed that PMVs up-regulated expression and activity of MMP-2 and MMP-9 in HUVECs, whereas PMVs did not affect VEGF-A, PDGF, HIF-1 $\alpha$, MMP-7, and TIMP-1 levels, and even decreased IL-8 mRNA level. These diverse actions of PMVs as revealed in the present study are in contrast to that reported by Mause et al. and may be due to different cell types used in the experiments. Further study is warranted to comprehensively and thoroughly explore the effects of PMVs on the modified endothelial cell secretome.

MMPs promote endothelial cell migration and tube formation by proteolytically remodelling the basement membrane $[2,38]$. Among these, MMP- 2 and MMP-9 have been emphasized because their type IV collagenase activity is essential during the initial phase of angiogenesis [20,39]. In the current study, we found that MMP-2 might play a more important role than MMP-9 in PMV-enhanced angiogenesis.

Certain signaling pathways, such as the ERK and Akt signaling pathways, are known to be involved in the expression of MMPs associated with angiogenesis [40,41]. As shown

\section{KARGER}


in Fig. $3 \mathrm{~F}$ and G, phosphorylated ERK (P-ERK) levels were significantly increased after 10 min of treatment with PMVs, while Akt signaling pathway activity levels were decreased. Consistent with the above observations, Brill et al. found that ERK is essential for PMVinduced angiogenesis since ERK inhibitors can reverse the pro-angiogenic effect of PMVs [9]. Besides, other signaling pathways, such as PI3K and Src pathways, may also play great roles in angiogenesis. Furthermore, our results showed that CD40L-CD40 and P-selectinPSGL-1 interactions were not involved in PMV-enhanced angiogenesis, which indicated that there might be other molecules carried by PMVs that relate to the pro-angiogenic activity. Therefore, it is necessary to identify the potential signaling pathways and molecules associated with PMV-enhanced angiogenesis in future studies.

We and others have confirmed the pro-angiogenic activity of PMVs in vivo [9]. Notably, PMVs may also exert adverse effects by promoting angiogenesis. We previously reported that plasma PMVs concentrations are higher in patients with acute coronary syndrome than in subjects with stable angina or healthy controls[42]. Moreover, several studies have demonstrated that platelet activation and high PMV levels are associated with atherosclerotic plaque progression $[43,44]$. Recently, intraplaque angiogenesis, which is characterized by immature and leaky microvessels, has been regarded as an important risk factor contributing to the development of intraplaque hemorrhage and plaque destabilization $[45,46]$. In addition, MMPs induce matrix degradation and cause fibrous cap thinning, which may also play great roles in atherosclerosis development. Therefore, further investigating whether and how PMVs are involved in atherosclerosis intraplaque angiogenesis is warranted.

In summary, we identified a novel mechanism by which PMVs promote EC angiogenic capacity and support vascular integrity maintenance after arterial injury. Specifically, we demonstrated for thefirsttimethatPMVsenhanceendothelialcellpro-angiogenicactivity byupregulating MMP-2/-9 expression and gelatinolytic activity, possibly through the ERK signaling pathway activation, while MMP-2 might play a more important role than MMP-9. Our data have provided us with insights regarding the novel idea that PMVs may promote angiogenesis by up-regulating MMP expression in ECs, in addition to directly transporting angiogenic factors. Besides, this finding also expands the possible importance of PMVs in the clinical conditions where pathogenesis is related to angiogenesis, such as plaque angiogenesis and intraplaque hemorrhage in atherosclerotic plaque destabilization [45-47].

\section{Disclosure Statement}

The authors declare no conflict of interest.

\section{Acknowledgements}

This work was supported by the grants from the National Natural Science Foundation of China (No. 81270362 and No. 81470561).

\section{Reference}

1 Eelen G, de Zeeuw P, Simons M, Carmeliet P: Endothelial cell metabolism in normal and diseased vasculature. Circ Res 2015;116:1231-1244.

2 Carmeliet P, Jain RK: Molecular mechanisms and clinical applications of angiogenesis. Nature 2011;473:298-307.

- 3 Logsdon EA, Finley SD, Popel AS, Mac Gabhann F: A systems biology view of blood vessel growth and remodelling. J Cell Mol Med 2014;18:1491-1508.

4 Rosenkilde MM, Schwartz TW: The chemokine system -- a major regulator of angiogenesis in health and disease. APMIS 2004;112:481-495.

5 Randi AM, Laffan MA: Von Willebrand factor and angiogenesis: basic and applied issues. J Thromb Haemost 2017;15:13-20. 


\section{Cellular Physiology Cell Physiol Biochem 2017;41:2319-2332 \begin{tabular}{l|l} 
and Biochemistry & DOI: 10.1159/000475651 2017 The Author(s). Published by S. Karger AG, Basel \\
(c) & www.karger.com/cpb
\end{tabular}

6 Burnouf T, Goubran HA, Chou ML, Devos D, Radosevic M: Platelet microparticles: detection and assessment of their paradoxical functional roles in disease and regenerative medicine. Blood Rev 2014;28:155-166.

7 Goubran HA, Burnouf T, Stakiw J, Seghatchian J: Platelet microparticle: a sensitive physiological "fine tuning" balancing factor in health and disease. Transfus Apher Sci 2015;52:12-18.

-8 Kim HK, Song KS, Chung JH, Lee KR, Lee SN: Platelet microparticles induce angiogenesis in vitro. Br J Haematol 2004;124:376-384.

-9 Brill A, Dashevsky 0, Rivo J, Gozal Y, Varon D: Platelet-derived microparticles induce angiogenesis and stimulate post-ischemic revascularization. Cardiovasc Res 2005;67:30-38.

10 Mause SF, Ritzel E, Liehn EA, Hristov M, Bidzhekov K, Muller-Newen G, Soehnlein O, Weber C: Platelet microparticles enhance the vasoregenerative potential of angiogenic early outgrowth cells after vascular injury. Circulation 2010;122:495-506.

11 Varon D, Shai E: Platelets and their microparticles as key players in pathophysiological responses. J Thromb Haemost 2015;13:S40-46.

12 Lee S, Chen TT, Barber CL, Jordan MC, Murdock J, Desai S, Ferrara N, Nagy A, Roos KP, Iruela-Arispe ML: Autocrine VEGF signaling is required for vascular homeostasis. Cell 2007;130:691-703.

13 Drusbosky L, Gars E, Trujillo A, McGee C, Meacham A, Wise E, Scott EW, Cogle CR: Endothelial cell derived angiocrine support of acute myeloid leukemia targeted by receptor tyrosine kinase inhibition. Leuk Res 2015;39:984-989.

14 Chang MC, Chen YJ, Liou EJ, Tseng WY, Chan CP, Lin HJ, Liao WC, Chang YC, Jeng PY, Jeng JH: 7-Ketocholesterol induces ATM/ATR, Chk1/Chk2, PI3K/Akt signalings, cytotoxicity and IL-8 production in endothelial cells. Oncotarget 2016;7:74473-74483.

15 Bei JJ, Liu C, Peng S, Liu CH, Zhao WB, Qu XL, Chen Q Zhou Z, Yu ZP, Peter K, Hu HY: Staphylococcal SSL5induced platelet microparticles provoke proinflammatory responses via the CD40/TRAF6/NFkappaB signalling pathway in monocytes. Thromb Haemost 2016;115:632-645.

-16 Jiang S, Li Y, Lin T, Yuan L, Li Y, Wu S, Xia L, Shen H, Lu J: IL-35 Inhibits Angiogenesis through VEGF/Ang2/ Tie2 Pathway in Rheumatoid Arthritis. Cell Physiol Biochem 2016;40:1105-1116.

17 Huang Z, Miao X, Luan Y, Zhu L, Kong F, Lu Q, Pernow J, Nilsson G, Li N: PAR1-stimulated platelet releasate promotes angiogenic activities of endothelial progenitor cells more potently than PAR4-stimulated platelet releasate. J Thromb Haemost 2015;13:465-476.

18 Nagase H, Woessner JF, Jr: Matrix metalloproteinases. J Biol Chem 1999;274:21491-21494.

19 Deryugina EI, Quigley JP: Matrix metalloproteinases and tumor metastasis. Cancer Metastasis Rev 2006;25:9-34.

20 Kessenbrock K, Plaks V, Werb Z: Matrix metalloproteinases: regulators of the tumor microenvironment. Cell 2010;141:52-67.

21 Sun DW, Zhang HD, Mao L, Mao CF, Chen W, Cui M, Ma R, Cao HX, Jing CW, Wang Z, Wu JZ, Tang JH: Luteolin Inhibits Breast Cancer Development and Progression In Vitro and In Vivo by Suppressing Notch Signaling and Regulating MiRNAs. Cell Physiol Biochem 2015;37:1693-1711.

-22 Corydon TJ, Mann V, Slumstrup L, Kopp S, Sahana J, Askou AL, Magnusson NE, Echegoyen D, Bek T, Sundaresan A, Riwaldt S, Bauer J, Infanger M, Grimm D: Reduced Expression of Cytoskeletal and Extracellular Matrix Genes in Human Adult Retinal Pigment Epithelium Cells Exposed to Simulated Microgravity. Cell Physiol Biochem 2016;40:1-17.

23 Qi C, Li B, Guo S, Wei B, Shao C, Li J, Yang Y, Zhang Q, Li J, He X, Wang L, Zhang Y: P-Selectin-Mediated Adhesion between Platelets and Tumor Cells Promotes Intestinal Tumorigenesis in Apc(Min/+) Mice. Int J Biol Sci 2015;11:679-687.

24 Bou Khzam L, Boulahya R, Abou-Saleh H, Hachem A, Zaid Y, Merhi Y: Soluble CD40 ligand stimulates the pro-angiogenic function of peripheral blood angiogenic outgrowth cells via increased release of matrix metalloproteinase-9. PLoS One 2013;8:e84289.

25 van Gils JM, Zwaginga JJ, Hordijk PL: Molecular and functional interactions among monocytes, platelets, and endothelial cells and their relevance for cardiovascular diseases. J Leukoc Biol 2009;85:195-204.

26 Lynch SF, Ludlam CA: Plasma microparticles and vascular disorders. Br J Haematol 2007;137:36-48.

27 Boilard E, Duchez AC, Brisson A: The diversity of platelet microparticles. Curr Opin Hematol 2015;22:437444.

28 Kim HK, Song KS, Park YS, Kang YH, Lee YJ, Lee KR, Kim HK, Ryu KW, Bae JM, Kim S: Elevated levels of circulating platelet microparticles, VEGF, IL-6 and RANTES in patients with gastric cancer: possible role of 


\section{Cellular Physiology Cell Physiol Biochem 2017;41:2319-2332 \begin{tabular}{l|l} 
and Biochemistry Published 10.1159/000475651 & $\begin{array}{l}\text { (c) } 2017 \text { The Author(s). Published by S. Karger AG, Basel } \\
\text { www.karger.com/cpb }\end{array}$
\end{tabular}

a metastasis predictor. Eur J Cancer 2003;39:184-191.

29 Moreno PR, Purushothaman KR, Sirol M, Levy AP, Fuster V: Neovascularization in human atherosclerosis. Circulation 2006;113:2245-2252.

-30 Prokopi M, Pula G, Mayr U, Devue C, Gallagher J, Xiao Q, Boulanger CM, Westwood N, Urbich C, Willeit J, Steiner M, Breuss J, Xu Q, Kiechl S, Mayr M: Proteomic analysis reveals presence of platelet microparticles in endothelial progenitor cell cultures. Blood 2009;114:723-732.

-31 Battinelli EM, Markens BA, Italiano JE, Jr.: Release of angiogenesis regulatory proteins from platelet alpha granules: modulation of physiologic and pathologic angiogenesis. Blood 2011;118:1359-1369.

-32 Huang Z, Miao X, Patarroyo M, Nilsson GP, Pernow J, Li N: Tetraspanin CD151 and integrin alpha6beta1 mediate platelet-enhanced endothelial colony forming cell angiogenesis. J Thromb Haemost 2016;14:606618.

-33 Aatonen M, Gronholm M, Siljander PR: Platelet-derived microvesicles: multitalented participants in intercellular communication. Semin Thromb Hemost 2012;38:102-113.

34 Gidlof O, van der Brug M, Ohman J, Gilje P, Olde B, Wahlestedt C, Erlinge D: Platelets activated during myocardial infarction release functional miRNA, which can be taken up by endothelial cells and regulate ICAM1 expression. Blood 2013;121:3908-3917.

35 Laffont B, Corduan A, Ple H, Duchez AC, Cloutier N, Boilard E, Provost P: Activated platelets can deliver mRNA regulatory Ago2.microRNA complexes to endothelial cells via microparticles. Blood 2013;122:253261.

-36 Vasina EM, Cauwenberghs S, Feijge MA, Heemskerk JW, Weber C, Koenen RR: Microparticles from apoptotic platelets promote resident macrophage differentiation. Cell Death Dis 2011;2:e211.

-37 Vasina EM, Cauwenberghs S, Staudt M, Feijge MA, Weber C, Koenen RR, Heemskerk JW: Aging- and activation-induced platelet microparticles suppress apoptosis in monocytic cells and differentially signal to proinflammatory mediator release. Am J Blood Res 2013;3:107-123.

-38 Li Y, Xie Y, Cui D, Ma Y, Sui L, Zhu C, Kong H, Kong Y: Osteopontin Promotes Invasion, Migration and Epithelial-Mesenchymal Transition of Human Endometrial Carcinoma Cell HEC-1A Through AKT and ERK1/2 Signaling. Cell Physiol Biochem 2015;37:1503-1512.

-39 Song H, Pan D, Sun W, Gu C, Zhang Y, Zhao P, Qi Z, Zhao S: SiRNA directed against annexin II receptor inhibits angiogenesis via suppressing MMP2 and MMP9 expression. Cell Physiol Biochem 2015;35:875884.

-40 Jin YJ, Park I, Hong IK, Byun HJ, Choi J, Kim YM, Lee H: Fibronectin and vitronectin induce AP-1-mediated matrix metalloproteinase-9 expression through integrin alpha(5)beta(1)/alpha(v)beta(3)-dependent Akt, ERK and JNK signaling pathways in human umbilical vein endothelial cells. Cell Signal 2011;23:125-134.

41 Wu F, Song H, Zhang Y, Zhang Y, Mu Q Jiang M, Wang F, Zhang W, Li L, Li H, Wang Y, Zhang M, Li S, Yang L, Meng Y, Tang D: Irisin Induces Angiogenesis in Human Umbilical Vein Endothelial Cells In Vitro and in Zebrafish Embryos In Vivo via Activation of the ERK Signaling Pathway. PLoS One 2015;10:e0134662.

-42 Sun C, Zhao WB, Chen Y, Hu HY: Higher Plasma Concentrations of Platelet Microparticles in Patients With Acute Coronary Syndrome: A Systematic Review and Meta-analysis. Can J Cardiol 2016;32:1325 e1321$1325 \mathrm{e} 1310$.

43 Lievens D, Zernecke A, Seijkens T, Soehnlein O, Beckers L, Munnix IC, Wijnands E, Goossens P, van Kruchten R, Thevissen L, Boon L, Flavell RA, Noelle RJ, Gerdes N, Biessen EA, Daemen MJ, Heemskerk JW, Weber C, Lutgens E: Platelet CD40L mediates thrombotic and inflammatory processes in atherosclerosis. Blood 2010;116:4317-4327.

44 Pamukcu B, Lip GY, Snezhitskiy V, Shantsila E: The CD40-CD40L system in cardiovascular disease. Ann Med 2011;43:331-340.

45 Doyle B, Caplice N: Plaque neovascularization and antiangiogenic therapy for atherosclerosis. J Am Coll Cardiol 2007;49:2073-2080.

46 Sluimer JC, Kolodgie FD, Bijnens AP, Maxfield K, Pacheco E, Kutys B, Duimel H, Frederik PM, van Hinsbergh VW, Virmani R, Daemen MJ: Thin-walled microvessels in human coronary atherosclerotic plaques show incomplete endothelial junctions relevance of compromised structural integrity for intraplaque microvascular leakage. J Am Coll Cardiol 2009;53:1517-1527.

47 de Vries MR, Quax PH: Plaque angiogenesis and its relation to inflammation and atherosclerotic plaque destabilization. Curr Opin Lipidol 2016;27:499-506. 